\title{
Analytical Calculation of Frequency Spectrum and Group Velocities of Acoustic Phonons in Quasi-two-dimensional Nanostructures
}

\author{
Yu.V. Lutsiuk, V.M. Kramar* \\ Yuriy Fedkovych Chernivtsi National University, 2, Kotsiubynsky St., 58012 Chernivtsi, Ukraine
}

(Received 23 March 2020; revised manuscript received 15 October 2020; published online 25 October 2020)

\begin{abstract}
Low-dimensional crystal structures that are attractive materials for the fabrication of modern nanoelectronic devices due to their unique physical properties are considered. Type of nanostructure (quantum well, quantum wire or quantum dot) and its sizes with respect to quasiparticle confined movement are determining factors for the formation of its mechanical, kinetic, optical and electronic properties and, since, main physical parameters. The processes of interaction between quasiparticles (in particular, electronphonon interaction) also play an important role. Renormalized energy spectra of electrons and phonons define the physical processes, which are produced by electron-phonon interaction in nanostructure. In order to understand these peculiarities, it is necessary to study how the energy spectra of both these systems of quasiparticles are transformed in nanostructures of different types and sizes, as well as mechanisms of their interaction. Therefore, one should know the analytical form of dispersion relation for the electron energy and frequencies of all types of phonons in a particular nanostructure. In this paper, we propose the method how to obtain the explicit dispersion relations for all modes of confined acoustic phonons in plane quasi-two-dimensional nanostructures with hexagonal crystal lattice. Using the dielectric continuum model, the formulas describing frequency as a function of the phonon wave vector are derived and phonon group velocity, in its turn. Computer simulations are performed for GaN nanofilm with wurtzite structure.
\end{abstract}

Keywords: Nanostructure, Nanofilm, Acoustic phonons, Frequency spectrum, Group velocity.

\section{INTRODUCTION}

Nanosized crystal structures and materials have been studied for a long time [1], however, interest to their research is still not declining [2,3]. Despite the great number of theoretical and experimental research works in this field, the theoretical description of electronphonon interaction in nanoheterostructures remains an actual problem. This interaction is an important factor in the processes of electrical and thermal conductivity, optical absorption, radiation, luminescence and Raman scattering in such systems [4]. It is particularly difficult to describe consistently the influence of acoustic phonons on these processes. The reasons lay in the discrepancy of some integrals in the expressions for the electronphonon binding functions and difficulties in calculating spectral dependences of the modes of the acoustic phonon spectrum in nanostructures. Therefore, the explicit expression for the function describing these dependences analytically is actual for the development of the theory of electron-phonon interaction in such structures.

In this paper, we propose a simple method to establish the analytical dependences of energies and velocities of acoustic phonons in a plane quasi-two-dimensional crystal nanostructure - nanofilm. It is based on the idea of expansion of components of the displacement vector of elastic vibrations of atoms in the crystal lattice into Fourier series. This gives an opportunity to find the analytical solution of equations of motion and the dispersion relation for frequency.

Computer simulations are performed for hexagonal structure of GaN type in order to compare the obtained results with the data presented by the authors of paper [5], who used the numerical methods.

\section{MODEL FOR THE PROBLEM AND METHOD OF ITS SOLUTION}

The processes of interaction between acoustic phonons and electrons in nanosized quasi-two-dimensional crystal structures can be described in the framework of an elastic continuum model using the method of deformation potential [6]. In this case, the Hamiltonian of the electron-phonon interaction is expressed within the functional dependences of frequency $\omega$ of elastic vibrations in a nanofilm on the magnitude of the wave vector $q$ and amplitudes of the displacement vector $u_{m}$ ( $m=1,2,3)$ on the coordinate $x_{3}$ along the direction of its surface, Fig. 1. Such dependences are obtained in this paper for all modes of the acoustic phonon spectrum in such quasi-two-dimensional crystal structures.

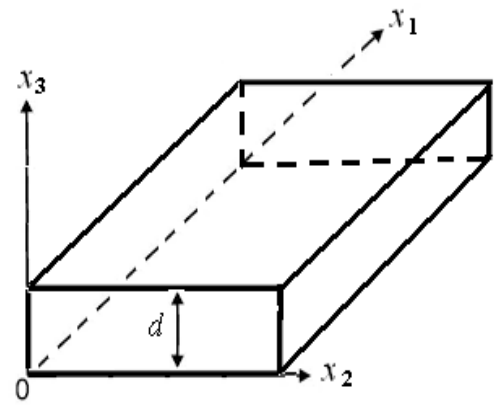

Fig. 1 - Geometrical scheme of a nanofilm

For the solution of the problem, like the authors of paper [5], we use the dielectric continuum model and equation of motion for the description of elastic vibrations in an anisotropic medium with mass density $\rho$

\footnotetext{
*v.kramar@chnu.edu.ua
} 


$$
\rho \frac{\partial^{2} U_{m}}{\partial t^{2}}=\frac{\partial \sigma_{m l}}{\partial x_{l}}
$$

where $U_{m}(m=1,2,3)$ are the components of the displacement vector, which are determined by the structure and elastic characteristics of the medium, such as the components of the mechanical stress tensor $\sigma_{m l}=c_{m l k j} U_{k j}$, where $c_{m l k j}$ and $U_{k j}=\mathrm{v}\left[\left(\partial U_{k} / \partial x_{j}\right)+\left(\partial U_{j} / \partial x_{k}\right)\right] / 2$ are the components of the elastic and strain tensors, respectively. Assuming that elastic vibrations are propagating along the $O x_{1}$ axis, the solution of the equation of motion is written in the form

$$
U_{m}\left(x_{1}, x_{3}, t\right)=u_{m}\left(x_{3}\right) \exp \left[-i\left(q x_{1}-\omega t\right)\right],
$$

where $i$ is the imaginary unit.

Substituting function (2) into equation (1) and taking into account the symmetry of the crystal lattice, we transform it to the form of the second order partial differential equation. In structures with the crystal lattice of hexagonal symmetry (wurtzite), the elastic properties are defined by a set of seven independent elastic constants: $c_{11}, c_{22}, c_{33}, c_{12}, c_{13}, c_{44}, c_{66}$. For such structures, these equations were obtained in [5] in the following form:

$$
-\rho \omega^{2} u_{2}\left(x_{3}\right)=c_{44} \frac{d^{2} u_{2}\left(x_{3}\right)}{d x_{3}^{2}}-c_{66} q^{2} u_{2}\left(x_{3}\right)
$$

for the transverse vibrations which are polarized in the plane of the layer (mode of shear vibrations) with boundary conditions

$$
\frac{d u_{2}\left(x_{3}\right)}{d x_{3}}=0
$$

For the two other polarizations, which are defined by the components of the displacement vectors $U_{1}$ and $U_{3}^{\prime}=-i U_{3}$, the equations of motion have the form of the system of equations

$$
\begin{aligned}
-\rho \omega^{2} u_{1}\left(x_{3}\right)=- & c_{11} q^{2} u_{1}\left(x_{3}\right)+c_{44} \frac{d^{2} u_{1}\left(x_{3}\right)}{d x_{3}^{2}}+ \\
& +\left(c_{13}+c_{44}\right) q \frac{d u_{3}^{\prime}\left(x_{3}\right)}{d x_{3}}, \\
-\rho \omega^{2} u_{3}^{\prime}\left(x_{3}\right)=- & c_{44} q^{2} u_{3}^{\prime}\left(x_{3}\right)+c_{33} \frac{d^{2} u_{3}^{\prime}\left(x_{3}\right)}{d x_{3}^{2}}- \\
& -\left(c_{13}+c_{44}\right) q \frac{d u_{1}\left(x_{3}\right)}{d x_{3}}
\end{aligned}
$$

with boundary conditions

$$
\frac{d u_{1}}{d x_{3}}+q u_{3}^{\prime}=0,-q c_{13} u_{1}+c_{33} \frac{d u_{3}^{\prime}}{d x_{3}}=0 .
$$

Superposition of these vibrations produces two independent modes in the spectrum of acoustic phonons in quasi-two-dimensional nanostructures: dilatational (SA) and flexural (AS) modes of normal vibrations [5].

Usually, the dispersion relation for these modes of confined acoustic vibrations is obtained within the solution of the system of equations (3), (4) and (5)-(7) using numerical methods. We propose the method of analytical solution of this problem.

At first, we present the unknown functions $u_{m}\left(x_{3}\right)$ $(m=1,2,3)$, limited in a segment $[0, d]$, within the cosine range

$$
u_{m}\left(x_{3}\right)=\sum_{n=0}^{\infty} a_{n} \cos \left(n \pi x_{3} / d\right)
$$

for the symmetric $(S)$ solution or within the sine range

$$
u_{m}\left(x_{3}\right)=\sum_{n=1}^{\infty} a_{n} \sin \left(n \pi x_{3} / d\right)
$$

for the asymmetric $(A)$ one. Substituting them into the system of differential equations (3), (4) and (5)-(7), we transform them into algebraic equations. The condition of existence of their solution determines the dispersion relations for all modes of confined acoustic phonons: shear, dilatational and flexural.

\section{RESULTS AND DISCUSSION}

\subsection{Spectrum of Acoustic Phonons in a Nanofilm}

Substituting (8) into equation (3) and taking into account the conditions (4), we get the dispersion relation for shear vibrations in a nanofilm with hexagonal crystal lattice in the form

$$
\omega_{n}^{s h}(q)=\sqrt{\frac{c_{66} q^{2}+c_{44}(n \pi / d)^{2}}{\rho}} .
$$

By analogy, using (5), (6) and taking into account (7), we get the dispersion relation

$$
\omega_{n}^{S A}(q)=\sqrt{\frac{F_{1 n}(q)+\sqrt{F_{2 n}(q)}}{2 \rho}}
$$

for dilatational phonons and

$$
\omega_{n}^{A S}(q)=\sqrt{\frac{F_{1 n}(q)-\sqrt{F_{2 n}(q)}}{2 \rho}}
$$

for flexural phonons. Here $n=1,2, \ldots$ is the quantum number (number of the vibrational state) and

$$
F_{1 n}(q)=\left(c_{11}+c_{44}\right) q^{2}+(n \pi / d)^{2}\left(c_{33}+c_{44}\right)
$$

or

$$
\begin{gathered}
F_{2 n}(q)=\left(c_{11}-c_{44}\right)^{2} q^{4}+2(n \pi / d)^{2}\left[2\left(c_{33}+c_{44}\right)^{2}-\right. \\
\left.-\left(c_{11}-c_{44}\right)\left(c_{33}-c_{44}\right)\right] q^{2}+(n \pi / d)^{4}\left(c_{33}-c_{44}\right)^{2}
\end{gathered}
$$

are the auxiliary functions. If $n=0$, expressions (9)-(11) define the dispersion relations for the frequencies of $T A_{2^{-}}, L A$ - and $T A_{1}$-modes of normal vibrations in $3 \mathrm{D}$ (bulk) crystal, respectively.

Using the obtained relationships and magnitudes which determine the structure and mechanical properties of $\mathrm{GaN}$ (wurtzite structure): lattice parameters $a_{0}=3.189 \AA, c_{0}=5.185 \AA, \rho=6.15 \mathrm{~g} / \mathrm{cm}^{3}$ [7] and elastic 
constants (in GPa) $c_{11}=390, c_{33}=398, c_{44}=105, c_{66}=123$, $c_{12}=145, c_{13}=106$ (according to A. Polian (1996), see in Ref. [8]), we present the dispersion curves for GaN nanofilms with different thicknesses in order to compare the results of analytical and numerical calculations presented in paper [5] at $d=6 \mathrm{~nm}$. Our results prove that calculated magnitudes of frequencies and character of their dependences on wave vector well correlate with data in [5].

The dispersion curves of shear phonons, Fig. 2, are almost the same as those presented in Fig. 1a in [5].

The similar results are observed for dilatational and flexural phonons, Fig. 3, and those, which are presented in Fig. 4d in [5].

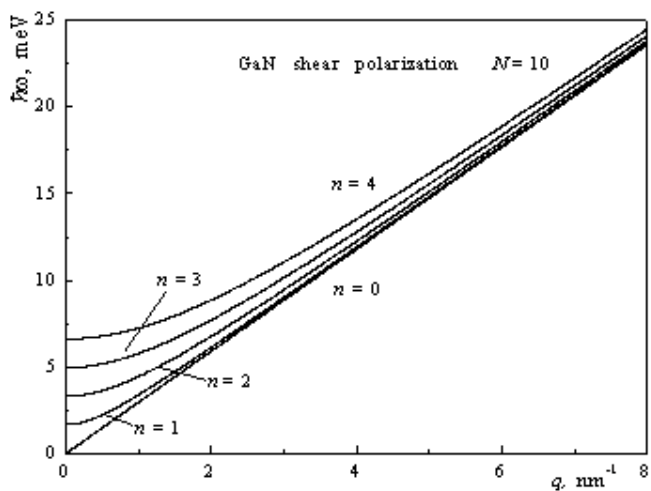

Fig. 2 - Energy spectrum of shear phonon mode in a nanofilm with a thickness of $N$ GaN monolayers

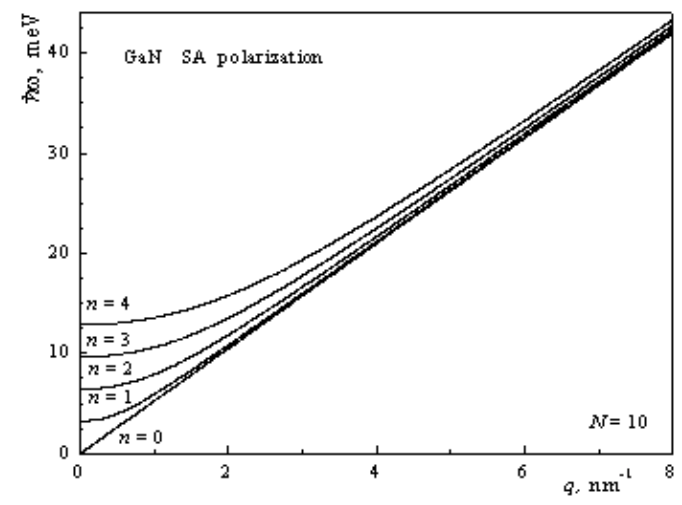

a

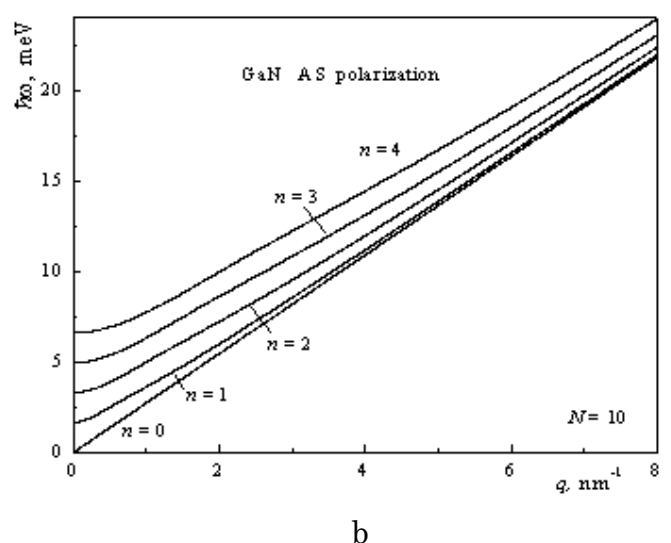

Fig. 3 - Energy spectrum of dilatational (a) and flexural (b) acoustic phonon modes in a nanofilm with a thickness of $N$ GaN monolayers
It is clear that due to the spatial confinement of acoustic phonons in a nanofilm, one can see the quasioptical states of these modes. The energies of these states $\hbar \omega_{n}(n=1,2, \ldots)$ at any $q$ exceed the energies of respective states in the bulk crystal $\hbar \omega_{0}$. The dependence $\hbar \omega_{n}(q)$ is nonlinear. These excesses are significant at small $q$, and as $q$ increases, the energies of all phonon states asymptotically tend to $\hbar \omega_{0}$.

Distances between dispersion curves $\hbar \omega_{n}(q)$ depend on the nanofilm thickness: they decay as it increases. Character of these functions is illustrated by behavior of the dispersion curves plotted at fixed $q$ for nanofilms with different thicknesses for dilatational phonon mode, Fig. 4.

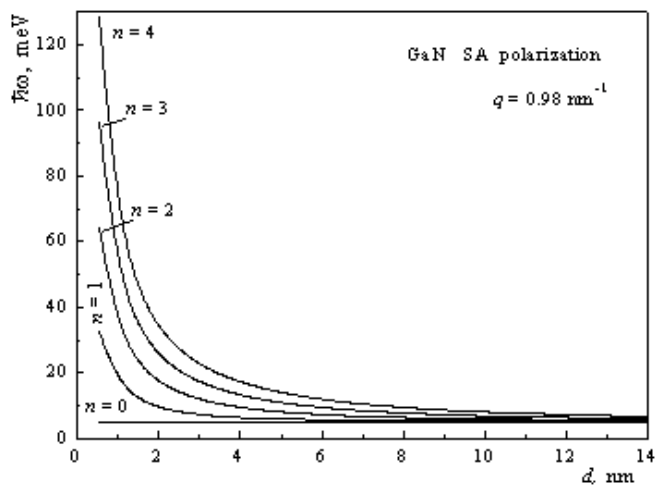

Fig. 4 - Energy of dilatational phonons as a function of nanofilm thickness

\subsection{Velocity of Acoustic Phonons}

Obtained functional dependences of frequency on the wave vector give an opportunity to establish dispersion and size dependences of group velocities $v$ of acoustic phonons in a nanofilm. Differentiating functions (9)-(11), we obtain

$$
v_{n}^{s h}(q)=\frac{c_{66} q}{\sqrt{\rho_{0}\left(c_{66} q^{2}+\left(\frac{\pi n}{d}\right)^{2} c_{44}\right)}}
$$

for shear mode and

$$
\begin{gathered}
v_{n}^{S A / A S}(q)=\left\{\left[\left(c_{11}+c_{44}\right) \sqrt{F_{2 n}(q)} \pm\left(\frac{n \pi}{d}\right)^{2}\left[2\left(c_{13}+c_{44}\right)^{2}-\right.\right.\right. \\
\left.\left.\left.-\left(c_{11}-c_{44}\right)\left(c_{33}-c_{44}\right)\right]\right] q \pm\left(c_{11}-c_{44}\right)^{2} q^{3}\right\} \times \\
\times\left[2 \rho_{0} F_{2 n}(q)\left(F_{1 q}(q) \pm \sqrt{F_{2 n}(q)}\right)\right]^{-1 / 2}
\end{gathered}
$$

for dilatational/flexural phonons.

Functions $v_{n}(q)$ in a nanofilm demonstrate dispersion, Fig. 5, on the contrary to the bulk crystal where group velocities of $L A-, T A_{1^{-}}$, and $T A_{2}$-modes of acoustic phonons are constant: $v_{L A} \equiv v_{0}^{S A}=\sqrt{c_{11} / \rho_{0}}=7963$, $v_{T A_{1}} \equiv v_{0}^{A S}=\sqrt{c_{44} / \rho_{0}}=4132, \quad v_{T A_{2}} \equiv v_{0}^{s h}=\sqrt{c_{66} / \rho_{0}}=4472 \mathrm{~m} / \mathrm{s}$. Herein, the velocities of shear and dilatational modes are smaller than the respective magnitudes in bulk crystals, see Fig. 5a, b. The difference between $v_{n}(q)$ and $v_{0}$ is bigger if the wave vector is smaller. Group velocities of these phonons monotonously increase. At 
bigger $q$ their magnitudes asymptotically, from below, tend to $v_{T A_{2}}$ and $v_{L A}$, respectively.

The dispersion dependence of group velocities of flexural phonons is nonmonotonic, Fig. 5c. Bigger $q$ causes their sharp increase from infinitely small magnitudes to maximal ones, which exceed the velocity of transverse $T A_{1}$-phonons in the bulk crystal. Further, the curves, like in cases shown in Fig. 5a, b, asymptoti- cally tend to $v_{T A_{1}}$, but from above.

Differences between the group velocities of different states of each mode of the acoustic phonon spectrum between each other and with respect to the magnitudes of corresponding velocities in the bulk crystal change when the nanofilm thickness varies, Fig. 6. It is absolutely clear for an ultra-thin nanofilm with a thickness of several GaN monolayers.

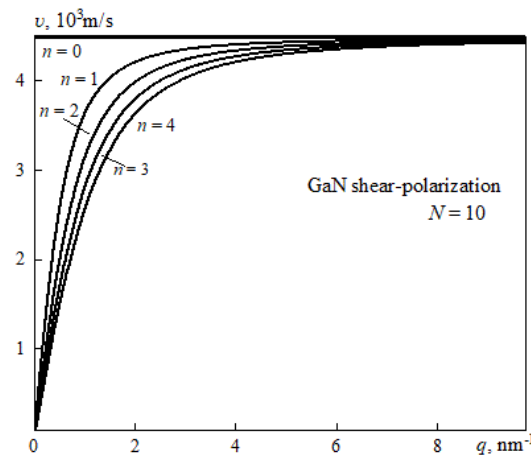

a

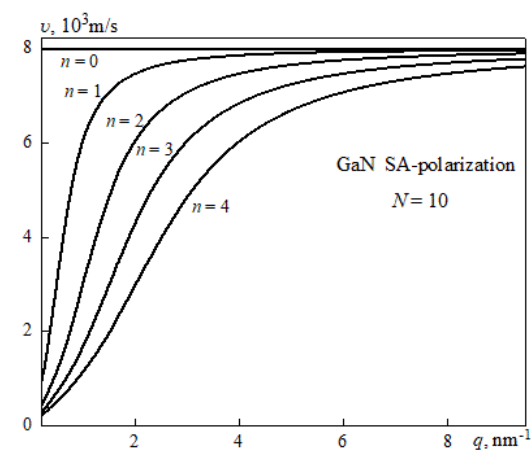

b

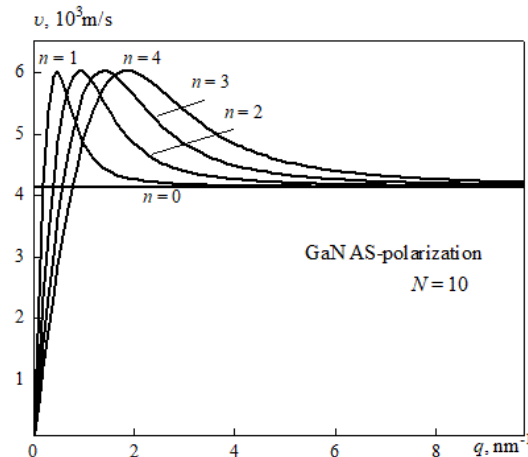

c

Fig. 5 - Spectral dependences of group velocities of phonon modes: (a) share; (b) dilatational; (c) flexural in a nanofilm with a thickness of $N$ GaN monolayers

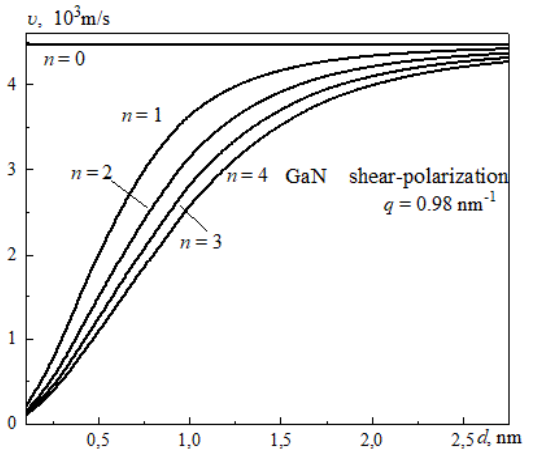

a

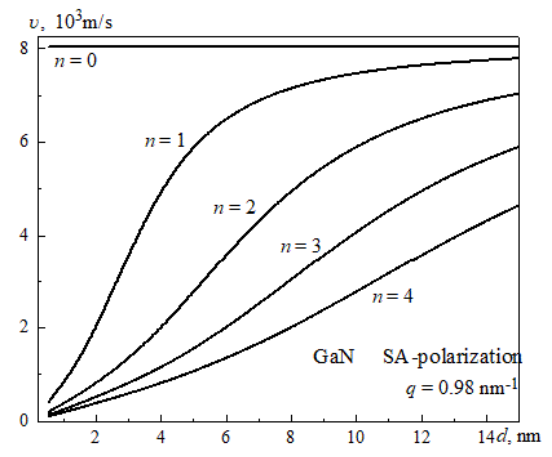

$\mathrm{b}$

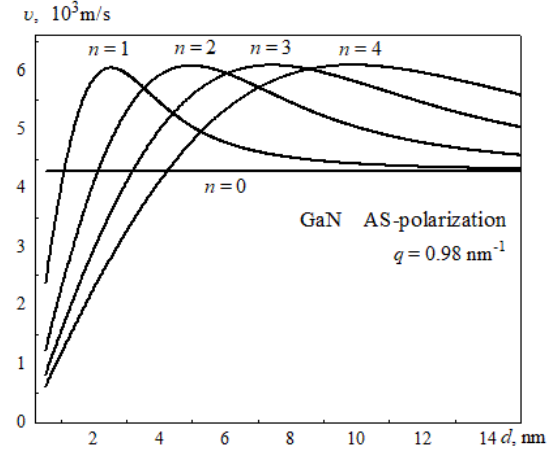

$\mathrm{c}$

Fig. 6 - Group velocities of acoustic phonons as functions of GaN nanofilm thickness for (a) shear; (b) dilatational; (c) flexural modes

We should note that the revealed character of the dispersion dependences of group velocities generally correlates with the results of numerical calculations presented in [5]. Our results for shear phonon mode, Fig. 5a, are almost the same as that shown in Fig. 2a of the cited paper. However, in case of SA-phonons, one can see essential differences: character of the dispersion curves presented in Fig. 5d, [5] is almost the same as we obtained for phonons of AS-polarization, but much more complicated. Dispersion functions for ASphonons are not presented in paper [5].

\section{CONCLUSIONS}

The method of obtaining an explicit expression for dispersion relations for frequencies of confined acoustic phonons in a nanofilm with hexagonal symmetry is proposed. Within the obtained information, it is possible to analyze and quickly calculate the structure of the frequency spectra, as well as the energies and group velocities of each mode of acoustic phonons in such nanostructures.
The results of calculations performed on the base of obtained relationships for wurtzite GaN nanofilms with different thicknesses prove the essential effect of spatial confinement on the structure of frequency-energy spectra of acoustic phonons in ultra-thin nanofilms the emergence of quasi-optical phonons. The frequencies of quantum states exceed the respective characteristic frequencies of atomic vibrations in the bulk crystal for all types of modes. Their dependences on the wave vector $q$ nonlinearly increase. Both these peculiarities are essential at small $q$ and are bigger for the smaller nanofilm thickness.

By analogy, the calculated magnitudes of phonon velocities for shear and dilatational modes monotonously increase at bigger $q$, being smaller than the respective $v_{T A_{2}}$ and $v_{L A}$ of the transverse and longitudinal phonons in the bulk crystal. These differences are also more essential at small magnitudes of the wave vector and nanofilm thickness.

Dispersion dependences of group velocities of flexural phonons are nonmonotonous. In the vicinity of small 
$q$, the velocities of all phonon states of this type sharply increase approaching their maximal values, which exceed velocity $v_{T A_{1}}$ of transverse $T A_{1}$-phonons in the bulk crystal. The location and height of the maximum are determined by the nanofilm thickness and the number of quantum states. Further increase in the wave vector causes the decrease in velocities of all quantum states of this mode of acoustic phonons and their asymptotical tend to $v_{T A_{1}}$, faster for the bigger nanofilm thickness.

Differences between the group velocities of different states of each mode of the acoustic phonon spectrum between each other and with respect to the magnitudes of respective velocities in the bulk crystal are clearly observed for ultra-thin films with a thickness of several GaN monolayers. Presented results correlate well with the data of ref. [5] obtained by the authors within the numerical methods.

The formulas proposed for the calculation of spectral dependences of frequencies and group velocities of acoustic phonons in nanofilms with the crystal lattice of hexagonal symmetry can be used in future for the investigation of the processes of thermal conductivity, electron scattering, electronic conductivity and optical absorption in quasi-two-dimensional nanostructures with this type of symmetry.

\title{
REFERENCES
}

1. Ja. Jeevanandam, A. Barhoum, Yen S. Chan, A. Dufresne and M.K. Danquah, Beilstein J. Nanotechnol. 9, 1050 (2018).

2. M.V. Kovalenko, L. Manna, A. Cabot, Z. Hens, D.V. Talapin, Ch.R. Kagan, V.I. Klimov, A.L. Rogach, P. Reiss, D.J. Milliron, $\mathrm{Ph}$. Guyot-Sionnnest, G. Konstantatos, W.J. Parak, T. Hyeon, B.A. Korgel, Ch.B. Murray, W. Heiss, ACS Nano 9 No 2, 1012 (2015).

3. T. Tsakalakos, In: Nanostructures: Synthesis, Functional Properties and Applications: NATO Science Series (Ser. II: Mathematics, Physics and Chemistry) 128 (Eds. T. Takalakos, I.A. Ovid'ko, A.K. Vasudevan) (Dordrecht: Springer: 2003).
4. M.P. Blencowe, Low-Dimensional Semiconductor Structures: Fundamentels and Device Applications (Red. K. Barnham, D. Vvedensky) (N-Y: Camdridge Univ. Press: 2001).

5. E.P. Pokatilov, D.L. Nika, A.A. Balandin, Superlattices Nanostruct. 33, 155 (2003).

6. E.P. Pokatilov, D.L. Nika, A.A. Balandin, J. Appl. Phys. 95, 5626 (2004)

7. A.A. Gorbatsevich, V.I. Yegorkin, V.Ye. Zemlyakov, Nanotechnology in electronics (Ed. by Yu.A. Chaplygin) (Moscow: Tekhnosphera: 2016) [in Russian] ISBN: 978-5-94836-422-3.

8. I. Vurgaftman, J.R. Meyer, L.R. Ram-Mohan, J. Appl. Phys. 89,5815 (2001)

\section{Аналітичний розрахунок спектра частот і групових швидкостей акустичних фононів у квазідвовимірних наноструктурах}

\author{
Ю.В. Луцюк, В.М. Крамар
}

\author{
Чернівецький національний університет, вул. Коцюбинського, 2, 54012 Чернівиі, Украйна
}

\begin{abstract}
Розглядаються низьковимірні напівпровідникові кристалічні структури, які через унікальність своїх фрізичних властивостей належать до привабливих матеріалів для створення новітніх пристроїв наноелектроніки. Тип (квантова яма, квантова нить чи квантова точка) та розміри обмеження руху квазічастинок у наноструктурі е визначальними факторами при формуванні їі механічних, кінетичних, оптичних та електронних властивостей, а отже й iї основних фізичних параметрів. Велику роль тут відіграють також процеси взаємодії квазічастинок, зокрема, електрон-фононної взаємодії. Перенормування енергетичних спектрів електронів і фононів у наноструктурі зумовлюе особливості перебігу в них процесів, що контролюються електрон-фононною взаємодією. Для розуміння џих особливостей необхідно досліджувати закономірності трансформації енергетичних спектрів обох систем квазічастинок у наноструктурах різного типу та розмірів, а також механізмів їх взаемодії. Це вимагае знання аналітичного вигляду залежності енергії електрона і частот фононів усіх можливих типів у конкретній наноструктурі. У даній роботі висвітлений спосіб встановлення явного вигляду законів дисперсії частот усіх гілок спектра обмежених акустичних фононів у плоских квазідвовимірних наноструктурах з гексагональною кристалічною граткою. У рамках моделі діелектричного континууму виведені dрормули, що описують залежність частоти від хвильового вектора фонона та, на цій основі, його групової швидкості. Конкретні розрахунки виконані на прикладі наноплівки $\mathrm{GaN}$ вюртцитної структури.
\end{abstract}

Ключові слова: Наноструктура, Наноплівка, Акустичні фонони, Частотний спектр, Групова швидкість. 